\title{
Internalisasi Nilai-Nilai Karakter Siri' na Pacce melalui Strategi Inkuiri pada Pembelajaran PPKn SMA
}

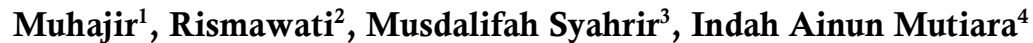

Prodi Pendidikan Pancasila dan Kewarganegaraan, Fakultas Keguruan dan Ilmu Pendidikan Universitas Muhammadiyah Makassar 1,2,3,4

\section{Informasi Artikel Abstrak}

Hisrtory of Article

Received 2020-11-03

Accepted 2021-01-20

Pusblished 2021-01-31

\section{Kata Kunci:}

Kata kunci :

Internalisasi, Nilai-

Nilai Karakter Siri' na

Pacce, Strategi Inkuiri,

PPKn

Keywords:

Internalization,

Character Values of

Siri' na Pacce, Inquiry

Strategy, Pancasila and Civic Education
Pendidikan karakter merupakan isu urgen yang harus terintegrasi dalam setiap kegiatan pembelajaran terutama pembelajaran Pendidikan Pancasila dan Kewarganegaraan. Oleh karena itu, artikel ini bertujuan untuk menganalisis Internalisasi Nilai-Nilai Karakter Siri' na Pacce melalui Strategi Inkuiri Pada Pembelajaran Pendidikan Pancasila dan Kewarganegaraan di Sekolah Menengah Atas. Penelitian ini menggunakan metode research and development (R\&D) dengan model ADDIE dan akan dilaksanakan di dua (2) sekolah yakni SMAN 2 Gowa dan SMAN 4 Takalar yang dipilih secara purposive dengan pendekatan kualitatif dan kuantitatif secara berkesinambungan guna mengetahui realitas proses pembelajaran Pendidikan Pancasila dan Kewarganegaraan. Hasil penelitian menunjukan bahwa internalisasi nilai-nilai karakter Siri' na Pacce melalui strategi Inkuiri pada pembelajaran Pendidikan Pancasila dan Kewarganegaraan di Sekolah Menengah Atas dilakukan melalui lima tahapan yakni; Tahap Orientasi, Tahap Merumuskan Masalah, Tahap Merumuskan Hipotesis, Tahap Mengumpulkan Data, Tahap Menguji Hipotesis, Tahap Merumuskan kesimpulan. Pada tahapan awal guru mengarahkan siswa berpikir pemecahan masalah yang berkaitan dengan pelanggaran nilai-nilai Siri' na Pacce dan kemudian membimbing siswa untuk mengikuti tahapan tersebut. Pada akhir tahapan guru menyimpulkan bersama siswa agar tidak terjadi perbedaan penafsiran nilai. Adapun nilai-nilai Siri' na Pacce yang di internalisasikan adalah Harga diri, Malu, Teguh Pendirian, Tepat Janji, Setia, dan Jujur.

Abstract
Character education is an urgent issue that must be integrated in every learning activity,
especially learning Pancasila and Civic Education. Therefore, this article aims to analyze
the internalization of the Siri 'na Pacce character values through inquiry strategies in
Pancasila and Civic Education in Senior High Schools. This research uses the research
and development (R\&D) method with the ADDIE model and will be carried out in two
(2) schools namely SMAN 2 Gowa and SMAN 4 Takalar which were selected purposively
with qualitative and quantitative approaches continuously to determine the reality of the
learning process of Pancasila and Civic Education. The results showed that the
internalization of the character values of Siri 'na Pacce through the Inquiry strategy of
learning Pancasila and Civic Education in Senior High Schools was carried out in five
stages, namely; Orientation Stage, Problem Formulation Stage, Hypothesis Formulation
Stage, Data Collecting Stage, Hypothesis Testing Stage, Formulating Conclusion Stage.
In the initial stages the teacher directs students to think about solving problems related to
violations of Siri 'na Pacce values and then guides students to follow these stages. At the


end of the stage the teacher concludes with the students so that there are no differences in the interpretation of values. The internalized values of Siri 'na Pacce are Self-esteem, Shyness, Firmness of Establishment, Right on Promise, Loyalty, and Honest.

(C) 2019, Universitas Negeri Semarang

Corresponding author: Muhajir

ISSN 2549-5011

Address: Jl. Sultan Alauddin No. 259 Makassar.

E-mail: muhajir@unismuh.ac.id

\section{PENDAHULUAN}

Pendidikan karakter merupakan upayaupaya yang dirancang dan dilaksanakan secara sistematis untuk membantu peserta didik memahami nilai-nilai perilaku manusia yang berhubungan dengan Tuhan Yang Maha Esa, diri sendiri, sesama manusia, lingkungan, dan kebangsaan yang terwujud dalam pikiran, sikap, perasaan, perkataan, dan perbuatan berdasarkan norma-norma agama, hukum, tata krama, budaya, dan adat istiadat. Ada empat jenis karakter yang selama ini dikenal dan dilaksanakan dalam proses pendidikan, yaitu: 1) Pendidikan karakter berbasis nilai religius, yang merupakan kebenaran wahyu tuhan (konservasi moral). 2) Pendidikan karakter berbasis nilai budaya, antara lain yang berupa budi pekerti, pancasila, apresiasi sastra, keteladanan tokoh-tokoh sejarah dan para pemimpin bangsa. 3) Pendidikan karakter berbasis lingkungan (konservasilingkungan). 4) Pendidikan karakter berbasis potensi diri, yaitu sikap pribadi, hasil proses kesadaran pemberdayaan potensi diri yang diarahkan untuk meningkatkan kualitas pendidikan (konservasi humanis), (Dodd, A. W, 1992:119120).

Salah satu proses pembelajaran yang memiliki peran penting dalam pendidikan karakter adalah pembelajaran Pendidikan Pancasila dan Kewarganegaraan (PPKn). Hal ini ditenggarai karena PPKn merupakan mata pelajaran yang didalamnya mengusung visi pendidikan karakter sesuai dengan amanat pasal 37 ayat (1) UU NO 20 tahun 2003 menyatakan bahwa 'Pendidikan kewarganegaraan dimaksudkan untuk membentuk peserta didik menjadi manusia yang memiliki rasa kebangsaan dan cinta tanah air.

Memperhatikan tujuan yang dikandung oleh PPKn, maka untuk mengimplementasikan pendidikan karakter perlu diupayakan proses pembelajaran yang bermakna dan kondusif.
Salah satu strategi pembelajaran yang dapat digunakan dalam proses pembelajaran ppkn dengan muatan pendidikan karakter adalah strategi pembelajaran inkuiri. Sebagai alternatif pembelajaran untuk meningkatkan kemampuan berpikir kritis mahasiswa melalui penyelidikan dan bimbingan, Joyce et al dalam Muhajir menyatakan latihan inquiri akan meningkatkan pemahaman ilmu pengetahuan, produktivitas dalam berpikir kreatif dan keterampilanketerampilan dalam memperoleh dan menganalis informasi, (Muhajir, 2018:42-46). Maka, inkuiri dapat digunakan oleh guru untuk menanamkan karakter pada proses pembelajaran karena strategi Inkuiri memuat metode penanaman karekter yang mengarahkan siswa untuk berproses memperoleh dan menganalisis informasi terkait karakter secara mandiri.

Berdasarkan temuan penelitian yang dilakukan di dua (2) SMAN 2 Gowa dan SMAN 4 Takalar diketahui bahwa saat ini pendidikan karakter merupakan sesuatu yang urgen untuk diimplementasikan pada proses pembelajaran terutama pembelajaran PKn di sekolah menengah atas. Akan tetapi, mengingat kondisi hari ini dimana Sulawesi selatan yang rentan menemui masalah terkait moral mulai dari begal yang dilakukan pelajar, tawuran antar pelajar, pergaulan bebas, yang kemudian marak ditampilkan pada berbagai media sosial seperti di Instagram (a)makassarinfo, dsb, memberikan dampak serta image negatif terhadap masyarkat terutama pelajar di wilayah Sulawesi selatan. Padahal Sulawesi selatan merupakan salah satu wilayah yang masyarakatnya menganut nilainilai baik yang di jadikan karakter dalam pergaulan sehari-hari yakni Siri' na Pacce'. Maka dari itu penelitian ini bertujuan untuk menganalisis Internalisasi Nilai-Nilai Karakter Siri' na Pacce melalui Strategi Inkuiri Pada Pembelajaran PPKn SMA. 


\section{METODE}

Artikel ini merupakan penelitian ini adalah Research and Development (R \& D) dengan pendekatan kualitatif dan kuantitatif. Menurut Richey \& Klein Akker (2015:141-150) dan Sugiyono penelitian pengembangan telah biasa digunakan dalam ilmu pendidikan terutama untuk membangun model yang akan mengaitkan antara teori yang ada dengan praktek yang terjadi di lapangan, (Sugiyono, 2015:458). Penelitian dilaksanakan pada 2 (Dua) SMAN di Sulawesi Selatan yakni SMAN 2 Kabupaten Gowa, SMA 4 Takalar. Pertimbangan pemilihan 2 (dua) sekolah latarbelakangi oleh letak sekolah yang berada di pusat ibukota Kabupaten yang masih kental dengan budaya Siri' na Pacce' namun terikat dengan kuatnya arus gaya hidup Kota Makassar.

\section{HASIL DAN PEMBAHASAN}

Penerapan pendidikan karakter dalam setiap mata pelajaran dapat dilakukan dengan menginternalisasikan nilai-nilai karakter yang hendak dicapai pada tiap tahap, yaitu perencanaan, pelaksanaan, dan evaluasi, termasuk juga dalam pembelajaran PPKn. PPKn merupakan mata pelajaran yang mengembang misi pengembangan karakter kebangsaan. Rohendi (2016) mengungkapkan bahwa PPKn bertujuan untuk membina moral agar terwujudnya kehidupan sehari-hari yang bertaqwa, berkemanusiaan yang adil dan beradab, perilaku yang mendukung persatuan bangsa dalam masyarakat yang beraneka ragam kepentingan, perilaku yang mendukung kerakyatan yang mengutamakan kepentingan bersama di atas kepentingan perorangan dan golongan sehingga perbedaan pemikiran, pendapatan, ataupun kepentingan di atas melalui musyawarah dan mufakat, serta perilaku yang mendukung upaya untuk mewujudkan keadilan sosial bagi seluruh rakyat Indonesia.

Maka dari itu, dapat dipahami bahwa pembelajaran $\mathrm{PKn}$ merupakan pembelajaran yang muatannya penuh dengan nilai-nilai karakter. Akan tetapi kenyataannya, pembelajaran PPKn dilaksanakan sama seperti pembelajaran berfokus pada pengembangan kemampuan berpikir siswa dan terkesan melupakan internalisasi nilai. Hasil temuan penelitian menunjukkan bahwa siswa cenderung bosan belajar karena pembelajaran ditekankan pada hafalan konsep. Sehingga siswa tidak mampu menghubungkan materi dengan kenyataan. Aspek sikap menjadi hal yang mustahil dalam pencapaian pembelajaran. Rohendi (2016) mengungkapkan dalam penelitiannya bahwa pembelajaran PKn yang berlangsung di kelas pada saat ini hanyalah sebatas pendidikan yang berorinetasi pada pencapaian tujuan kognitif atau pengetahuan saja.

Kondisi memicu pada keadaan bahwa harus ada inovasi dalam penginternalisasikan nilai-nilai melalui pembelajaran PPKn. Inovasi ini dilakukan dengan menggunakan strategi Inkuiri karena Pembelajaran dengan menggunakan strategi inkuri berangkat dari asumsi bahwa sejak lahir ke dunia, manusia memiliki dorongan untuk menemukan sendiri pengetahuannya, (Rusman, 2017). Inkuiri diasumsikan cocok untuk menginternalisasikan nilai karakter karena Pendidikan Kewarganegaraan mendorong siswa untuk menjadikan siswa; (1) mampu berpikir kritis, rasional, dan kreatif; (2) mau berpartisipasi secara aktif dalam segala bidang kegiatan dan bertanggung jawab; (3) dapat berkembang secara positif dan demokratis untuk membentuk diri berdasarkan karakter-karakter masyarakat Indonesia agar dapat hidup bersama dengan bangsa-bangsa lainnya; (4) mampu berinteraksi dengan bangsa-bangsa lain baik secara langsung atau tidak langsung dengan memanfaatkan teknologi dan informasi, (Yuliantoro, 2015).

Dalam penelitian ini, muatan nilai yang diinternalisasikan bukan hanya sekedar nilai kebangsaan yang telah termuat dalam PPKn. Namun juga mengaitkan dengan nilai-nilai kearifan local setempat yakni Siri' na Pacce. Budaya Siri' na Pacce merupakan salah satu falsafah budaya masyarakat Bugis, Makassar, Mandar yang harus dijunjung tinggi. Apabila Siri' na Pacce tidak dimiliki seseorang, maka orang tersebut dapat melebihi tingkah laku binatang, sebab tidak memiliki rasa malu, harga diri, dan kepedulian sosial. Istilah Siri' na Pacce sebagai sistem nilai budaya sangat abstrak dan sulit untuk didefenisikan karena Siri' na Pacce hanya bisa dirasakan oleh penganut budaya itu. Bagi masyarakat Bugis-Makassar, Toraja dan Mandar Siri' mengajarkan moralitas kesusilaan yang berupa anjuran, larangan, hak dan kewajiban yang mendominasi tindakan manusia untuk menjaga dan mempertahankan diri dan kehormatannya. Beradasarkan nilai-nilai yang terkandung budaya Siri' na Pacce terbagi atas 3 yaitu: Nilai Filosofis, Nilai Etis, Nilai Estetis.

Dengan demikian, nilai-nilai siri' ini memiliki pengaruh besar bagi sikap hidup 
masyarakat Bugis-Makassar dan masyarakat Sulawesi Selatan secara umum. Sehingga nilai siri' ini bagi masyarakat Bugis-Makassar, sebagaimana yang telah diuraikan diatas adalah sebuah falsafah hidup, dimana secara garis besar dapat ditarik sebuah benang merah berdasarkan analisaanalisa diatas, bahwa sesungguhnya peranan siri' yang merupakan alam bawah sadar masyarakat Bugis-Makassar ini merupakan nilai falsafah dan sikap yang menjadi perwujudan dari manusia Bugis-Makassar, (Muhdina, 2015). Internalisasi Nilai-Nilai Karakter Siri' na Pacce melalui Strategi Inkuiri Pada Pembelajaran PPKn SMA yang dilakukan dalam penelitian ini memuat muatan nilai sebagai berikut; Harga diri, Malu, Tegus Pendirian, Tepat janji, Setia, Jujur.

Berikut langkah yang digunakan dalam menginternalisasikan Nilai-Nilai Karakter Siri' na Pacce melalui Strategi Inkuiri Pada Pembelajaran PPKn:

1. Tahap Orientasi: guru mengondisikan agar siswa siap melaksanakan proses pembelajaran, guru merangsang dan mengajak siswa untuk berpikir memecahkan masalah dan mengaitkan dengan muatan nilai yang disusun.

2. Tahap Merumuskan Masalah: langkah membawa siswa pada suatu persoalan yang mengandung teka-teki. Persoalan yang disajikan adalah persoalan yang menantang siswa untuk berpikir memecahkan teka-teki itu dan merumuskan nilai apa yang dilanggar.

3. Tahap Merumuskan Hipotesis: Guru mengajukan berbagai pertanyaan yang dapat mendorong siswa untuk dapat merumuskan jawaban sementara atau dapat merumuskan berbagai perkiraan kemungkinan jawaban dan suatu permasalahan yang dikaji.

4. Tahap Mengumpulkan Data: aktivitas menjaring informasi yang dibutuhkan untuk menguji hipotesis yang diajukan. Dalam strategi pembelajaran inkuiri, mengumpulkan data merupakan proses mental yang sangat penting dalam pengembangan intelektual.

5. Tahap Menguji Hipotesis: Proses menentukan jawaban yang dianggap diterima sesuai dengan data atau informasi yang diperoleh berdasarkan pengumpulan data.

6. Tahap Merumuskan kesimpulan: Proses mendeskripsikan temuan yang diperoleh berdasarkan hasil pengujian hipotesis

\section{SIMPULAN}

Pengimplementasian pendidikan karakter di sekolah memiliki dinamika dan pencirian masing-masing yang tidak terlepas dari tujuan pendidikan nasional. Pencirian tersebut terdapat melalui sentuhan budaya lokal pada setiap proses pembelajaran dengan berbagai strategi pembelajaran salah satunya strategi ingkuiry. Pembelajaran dengan menggunakan langkah strategi inkuri dalam penginternalisasian nilai karakter Sirri Na Pacce berangkat dari asumsi bahwa setiap peserta didik dapat menemukan sendiri pengetahuannya dan lebih bermakna (meaningfull) manakala di peroleh atau didapatkan berdasarkan keingintahuan sendiri. Langkah-langkah tersebut terdiri atas Tahap Orientasi, Tahap Merumuskan Masalah, Tahap Merumuskan Hipotesis, Tahap Mengumpulkan Data, Tahap Menguji Hipotesis, Tahap Merumuskan kesimpulan.

\section{DAFTAR PUSTAKA}

Colburn, A. (2000). An Inquiry Primer. Science Scope, 42-44.

Dodd, A. (1992). Educating for Character: How Our Schools Can Teach Respect and Responsibility. New York: Bantam Books.

Gay, G. (2013). Teaching To and Through Cultural Diversity. Curriculum Inquiry, 48-70.

Indonesia, R. (2003). Undang-Undang Nomor 20 Tahun 2003 tentang Sistem Pendidikan Indonesia. Jakarta.

Muhajir, Bundu, P., \& Ahmad, A. (2018). Inquiry Learning Strategy to Improve Student's Critical Thinking Skills. Journal of Research and Method in Education (JRME), 42-46.

Muhdina, D. (2015). Kerukunan Umat Beragama Berbasis Kearifan Lokal di Kota Makassar. Diskursus Islam, 20-36.

Richey, R. C., \& Klein, J. D. (2014). Design and Development Research. New York: Lawrence Erlbaum Associates, Inc.

Rohendi, E. (2016). Pendidikan Karakter di Sekolah. EduHumaniora. 
Muhajir Rismawati, Musdalifah Syahrir, Indah Ainun Mutiara/INTEGRALISTIK Volume (1) (2021)

Rusman. (2017). Belajar dan Pembelajaran: Berorientasi Standar Proses Pendidikan. Jakarta: PT Kharisma Putra Utama.

Sugiyono. (2015). Metode Penelitian Bisnis. Pendekatan Kuantitatif, kualitatif dan $R \&$ $D$. Bandung: Alfabeta.

Yuliantoro, T. (2015). Indigenous Constitution Dalam Perspektif Ketatanegaraan dan Fikih Minoritas. IN RIGHT, 457-512. 